\title{
Estruturas primárias e tectônicas do Anortosito Capivarita, Pântano Grande (RS): significado e implicações na sua evolução petrológica
}

\author{
Ruy Paulo Philipp ${ }^{1}$, Milton Luiz Liquintinie Formoso ${ }^{1}$, Ivo Dossin ${ }^{2}$, Farid Chemale Jr ${ }^{2}$ \\ \& Roberto Sacks de Campos ${ }^{3}$
}

\begin{abstract}
Resumo O Anortosito Capivarita é uma unidade de idade Mesoproterozóica, constituída por anortositos, com presença subordinada de anortositos com granada, metagabros e anfibolitos. Apresenta relações intrusivas com os paragnaisses de alto grau do Complexo Várzea do Capivarita e encontra-se como pendentes de teto nos Granitos Encruzilhada do Sul e Pitangueiras, de idade Neoproterozóica. Estudos estruturais, petrográficos e mineralógicos caracterizaram os anortositos e os gabros como representantes de um magmatismo metaluminoso relacionado a série tolética. Os protólitos são dominados por anortositos, com ocorrência de corpos tabulares de composição gabróica e níveis de granada anortositos e rochas ricas em óxidos de $\mathrm{Fe}$-Ti, constituindo uma associação de anortosito do tipo maciço. A estrutura bandada é definida por variação composicional e de tamanho de grão, indicando que os anortositos apresentam uma evolução relacionada a processos de fracionamento mineral. As feições estruturais, petrográficas e os padrões composicionais são muito similares aos descritos em anortositos de idade Paleoproterozóica. A presença dominante de anortositos, com anfibolitos associados sugere que a porção principal desta associação pode representar acumulações de plagioclásio formadas pelo fluxo magmático e/ou por flotação, associada ao assentamento gravitacional. As feições estruturais primárias e composicionais dos anortositos sugerem que este magmatismo ocorreu sob condições anorogênicas, em um ambiente estável, provavelmente cratônico. Após a sua cristalização o anortosito foi afetado por um evento de metamorfismo regional orogênico sob condições da fácies anfibolito superior a Granulito.
\end{abstract}

Palavras-chave: Anortosito Capivarita, gabros, tipo maciço, septos do embasamento, Cinturão Dom Feliciano.

\begin{abstract}
Primary and tectonics structures of Capivarita Anortosite, Pântano Grande, RS: meaning and implication from petrologic evolution. The Capivarita Anorthosite is a unit of Mesoproterozoic age constituted by anorthosite with subordinate presence of garnet anorthosite, metagabros and amphibolites. The anorthosite shows intrusive relationship with high degree paragneisses of Várzea do Capivarita Complex and occurs as a roof pendant in the Neoproterozoic Encruzilhada do Sul and Pitangueiras granites. Structural, petrographic and mineralogical studies characterized the anorthosite and amphibolites as magmatism probably related to tholeitic series. The protoliths are dominated by anorthosites with occurrence of garnet anorthosites and rocks rich in Fe-Ti oxides, constituting an association of massif-type anorthosite. The banded structure is defined by regular variations in composition and size of grains, probably related to mineral fractionation process. The structural, petrographic and mineralogical features are similar to anorthosites of paleoproterozoic ages. The dominant presence of anorthosites with associated amphibolites and metagabbros suggests that the main portion of this association can represent plagioclase cumulates generated by magmatic flux and/or flotation by gravitational assent. The primary structural features suggest this magmatism occurred in anorogenic conditions, in a stable environment, probably cratonic. After this crystallization the anorthosite was submited to regional metamorphism of high degree conditions.
\end{abstract}

Keywords: Capivarita Anortosite, gabro, massif type, basement septs, Dom Feliciano Belt.

INTRODUÇÃo Os anortositos são rochas singulares (unique) e apesar do pouco volume crustal são identificados principalmente em terrenos Arqueanos e Proterozóicos de todos os continentes, com expressivas ocorrências na América do Norte, África, Europa e Antártica. Estão presentes desde o inicio do desenvolvimento do sistema solar como podemos constatar a partir de sua abundância na crosta da Lua (Heather \&
Dunkin 2003; Takeda et al. 2006).

A origem dos anortositos é um tema em constante discussão e são diversos os exemplos mundiais que descrevem sua geração como relacionada à diferenciação de magmas mantélicos ou a partir da fusão de rochas crustais. $\mathrm{O}$ fracionamento de magmas mantélicos de composição básica é indicado na formação de anortositos do tipo maciço como o Kunene Intrusive Com-

1 - Universidade Federal do Rio Grande do Sul, Instituto de Geociências, Centro de Estudos em Petrologia e Geoquímica (CPGq), Porto Alegre (RS), Brasil. Pesquisadores do CNPq. E-mail: ruy.philipp@ufrgs.br; milton.formoso@ufrgs.br

2 - Universidade de São Paulo, Instituto de Geociências, São Paulo (SP), Brasil.

3 - Universidade de Brasília, Instituto de Geociências, Brasília (DF), Brasil. 
plex, Angola-Namíbia (Mayer et al. 2004; Drüppel et al. 2007), Labrador Anorthosite, Canadá (Morse 2006), Bjerkrein-Sokndal Intrusion, Noruega (Wilson \& Overgaard 2005), Bengal Anorthosite, India (Mukherjee et al. 2005), Tin Zebane Layered Intrusion, Argélia (AïtDjafer et al. 2003) e Oranjekom Anorthosite, África do Sul (Geringer et al. 1998), entre outros. A fusão de rochas máficas crustais em porções profundas de antigos cinturões colisionais continentais é postulada para a geração de anortositos em associação com gabros e com granitos tipo rapakivi como descritos na Koperberg Suíte, África do Sul (Geringer et al. 1998; Duschesne et al. 2007), no Korosten Complex, Ucrânia (Bogdanova et al. 2004; Shumlyanskyy et al. 2006), Laramie Anorthosite, USA (Scoates et al. 2003) e no magmatismo tardia pós-colisional do Cinturão Araçuai-Ribeira, Espirito Santo (Wiedeman et al. 2002).

Anortositos também são rochas importantes na reconstrução e na evolução dos antigos continentes, como o Columbia (pré-Rodínia) e o Rodínia, ocorrendo nos estágios finais de consolidação continental (período pós-colisional) ou posteriormente, nos estágios precoces de fragmentação continental (Zhao et al. 2004; Zhai \& Liu 2003; Mukherjee \& Das 2003).

Além de sua importância petrológica e geotectônica, os anortositos ainda constituem importante fonte para minérios de ferro, titânio, fósforo, elementos do grupo da platina, níquel e cobre (Charlier et al. 2006, 2007; Mukherjee et al. 2005; Areback \& Stigh 2000), bem como caulim e alumínio (Schenato \& Formoso 1993).

Anortositos do tipo-maciço se caracterizam por grandes volumes de anortositos com presença subordinada de gabros, rochas ricas em óxidos de Fe-Ti, monzonitos, sienitos e charnockitos, comumente comagmáticos. A maior parte das ocorrências está associada com rochas máficas plutônicas em terrenos de médio a alto grau metamórfico de idade Paleoproterozóica e se notabilizam pela ausência de ultramafitos. Os anortositos do tipo-maciços são comuns em escudos de todos os continentes, destacando-se as amplas ocorrências nos terrenos pré-cambrianos da América do Norte (Canadá e Estados Unidos), Europa (Noruega, Ucrânia), África (Angola, Namíbia, Madagascar e África do Sul) e Ásia (Índia e China).

Os corpos possuem formas variadas entre dômicas e lacolíticas, resultantes de uma complexa estruturação interna relacionada ao caráter multi-intrusivo e polifásico de fases comagmáticas. $\mathrm{O}$ posicionamento das unidades está relacionado comumente a estruturas tectônicas como falhas extensionais e zonas de cisalhamento, variando de rúpteis a dúcteis. Os processos de posicionamento (emplacement) são complexos, com episódios magmáticos cíclicos, que envolvem ascenção diapírica, fracionamento mineral, com assentamento gravitacional, flotação e separação de fases associada ao diapirismo e ao posicionamento final controlado por falhas (Auwera et al. 2006; Higgins 2005; Reddy \& Leelanandam 2004; Wiedemann et al. 2002; Barnichon et al. 1999; Borradaile et al. 1998; Lafrance et al. 1998).

Em geral, os anortositos possuem granulação grossa, estruturação interna bandada e teor de mi- nerais máficos entre 5 e $10 \%$. São reconhecidos dois grupos distintos de anortositos do tipo-maciço, que se classificam como andesina e labradorita, em função da composição do plagioclásio. Os dados geoquímicos e isotópicos comumente apontam para uma evolução relacionada ao fracionamento de magmas básicos de natureza toleítica ou, menos freqüente, a magmas andesíticos de caráter cálcico-alcalino. A ocorrência de anortositos está relacionada tanto a ambientes geotectônicos estáveis como áreas cratônicas do Arqueano e do Paleoproterozóico, como em cinturões orogênicos de idade paleo a neoproterozóicas, onde estão comumente associados ao período pós-colisional.

O Anortosito Capivarita constitui um fragmento do embasamento do Cinturão Dom Feliciano e representa a principal ocorrência de anortosito tipo-maciço na região sul do Brasil (Formoso 1973). Este trabalho apresenta os dados estruturais, petrográficos e mineralógicos com objetivo de caracterizar as condições de sua geração e posicionamento, bem como avaliar as prováveis fontes e ambientes tectônicos dos protólitos. Também serão investigadas as condições da superposição do metamorfismo regional através do estudo das microestruturas e das relações entre as foliações magmáticas e tectônicas.

TRABALHOS ANTERIORES O reconhecimento do Anortosito Capivarita e suas relações com as rochas encaixantes foi apresentado inicialmente por Carraro \& Formoso (palestra convidada do Congresso Brasileiro de Geologia, 1962), e publicado posteriormente, por Tessari \& Picada (1966) e Ribeiro et al. (1966). Formoso \& Carraro (1968) descreveram as principais características petrográficas e mineralógicas, com ênfase na formação de caulinita como produto de alteração, que é o principal insumo mineral obtido a partir desta unidade. Posteriormente, Formoso (1973) reconheceu três corpos de anortositos e definiu a alteração intempérica como responsável pela formação de importantes reservas de argilas contendo misturas de caulinita e halloysita. Formoso et al. (1975) reconheceram o anortosito como sendo do tipo maciço, pela dominância de anortositos entre as rochas do complexo, presença de grandes cristais de plagioclásio e pela constância da composição do plagioclásio (labradorita), com ocorrência restrita de Bytownita associada a um nível de anortosito com granada. A alteração hidrotermal do anortosito é relacionada ao caráter intrusivo e pós-tectônico do Granito Encruzilhada. Trabalhos mais recentes de Fernandes et al. (1988) reconheceram a atuação de processos tectônicos e metamórficos no anortosito, cuja evolução é interligada aos complexos metamórficos Várzea do Capivarita e Arroio dos Ratos. Uma definição mais precisa dos limites e das relações de contato do anortosito estão associados com os trabalhos de Ramgrab et al. (1993) e Vasquez (1997).

\section{GEOLOGIA E RELAÇÕES ESTRUTURAIS O}

Anortosito Capivarita ocorre na região de Capivarita, município de Pântano Grande, porção nordeste do Escudo Sul-Rio-Grandense, compondo o embasamento do Batólito Pelotas, uma extensa área de rochas gra- 
níticas que constitui a porção central do Cinturão Dom Feliciano (Figs. 1 e 2).

O Anortosito Capivarita ocorre como três corpos principais, que apresentam formas alongadas segundo a direção $\mathrm{NS}$ e $\mathrm{N} 30^{\circ} \mathrm{E}$, com cerca de 20 e 25 quilômetros de comprimento e 10 a 7 quilômetros de largura, respectivamente (Fig. 3). O corpo mais ao noroeste ocorre como um pendente de teto (roof pendant) na fácies equigranular do Granito Encruzilhada do Sul, sendo encoberto ao norte e ao oeste por arenitos da Bacia do Paraná. A maior parte dos contatos do anortosito com os gnaisses do Complexo Várzea do Capivarita (CVC) são tectônicos, definidos por uma zona de cisalhamento rúptil. Contatos intrusivos preservados na porção norte de ambos os corpos descritos por Ribeiro et al. (1966). O corpo situado ao leste constitui um pendente de teto no Granito Pitangueiras, mantendo na sua porção leste, contato tectônico e de natureza rúptil com a fácies porfirítica do Granito Encruzilhada do Sul, definido por um segmento da Zona de Cisalhamento Passo dos Marinheiros.

Os afloramentos são raros, ocorrendo duas áreas principais situadas nas proximidades das sedes das fazendas Santo Antônio-Dom Felipe e Porteirinha, compondo lajeados e campos de matacões de dezenas de metros por centenas de metros de extensão. Ambos os corpos são constituídos predominantemente por anortositos, com ocorrência subordinada de granada anortositos, Anfibolitos, metagabros e finos níveis de rochas ricas em óxidos de Fe-Ti. O Anortosito Capivarita está afetado por um evento de metamorfismo regional orogênico, onde os efeitos da deformação causam a obliteração parcial das estruturas ígneas e a substituição das texturas magmáticas por arranjos metamórficos. Apesar da atuação dos processos tectônicos, é abundante a preservação das estruturas primárias.

O Anortosito Capivarita é do tipo maciço, apresenta cor branca, textura equigranular média a grossa, composição homogênea e teor de máficos entre 2 e 5 $\%$. A estrutura principal é caracterizada por um bandamento incipiente, descontínuo e irregular, definido principalmente por finos agregados de minerais máficos, e subordinadamente pela orientação dimensional do plagioclásio nos níveis félsicos. $\mathrm{O}$ anfibólio ocorre em níveis descontínuos e mostra-se orientado segundo uma lineação de origem tectônica. São identificados três tipos de bandamentos ígneos no anortosito.

A estrutura mais definida é a intercalação de camadas isomodais com alternância mineral. Os níveis félsicos e dominantes ricos em plagioclásio, têm disposição contínua e regular, com espessura centimétrica. Os níveis máficos são descontínuos, irregulares e têm espessuras milimétricas (1 a $5 \mathrm{~mm}$ ), compostos por hornblenda e raro diopsídio (Fig. 4a). O anortosito ainda apresenta variação gradacional na concentração de silicatos máficos nas camadas, incluindo os teores de hornblenda, titanita e óxidos de Fe-Ti (ilmenita e magnetita) e grossulária, que podem oscilar entre 2 a 10 \% (Fig. 4b). De modo restrito, observa-se variação de tamanho de grão entre as camadas, com alternância de camadas de espessuras métricas com níveis de granulação média a grossa, muito grossa e pegmatóide (Fig. 4c). No principal afloramento da fazenda Porteirinha, ocorre uma única camada contínua de granada anortosito com espessura de cerca de 15 a 20 centímetros e extensão aflorante de cerca de 30 metros. Os contatos são defini-

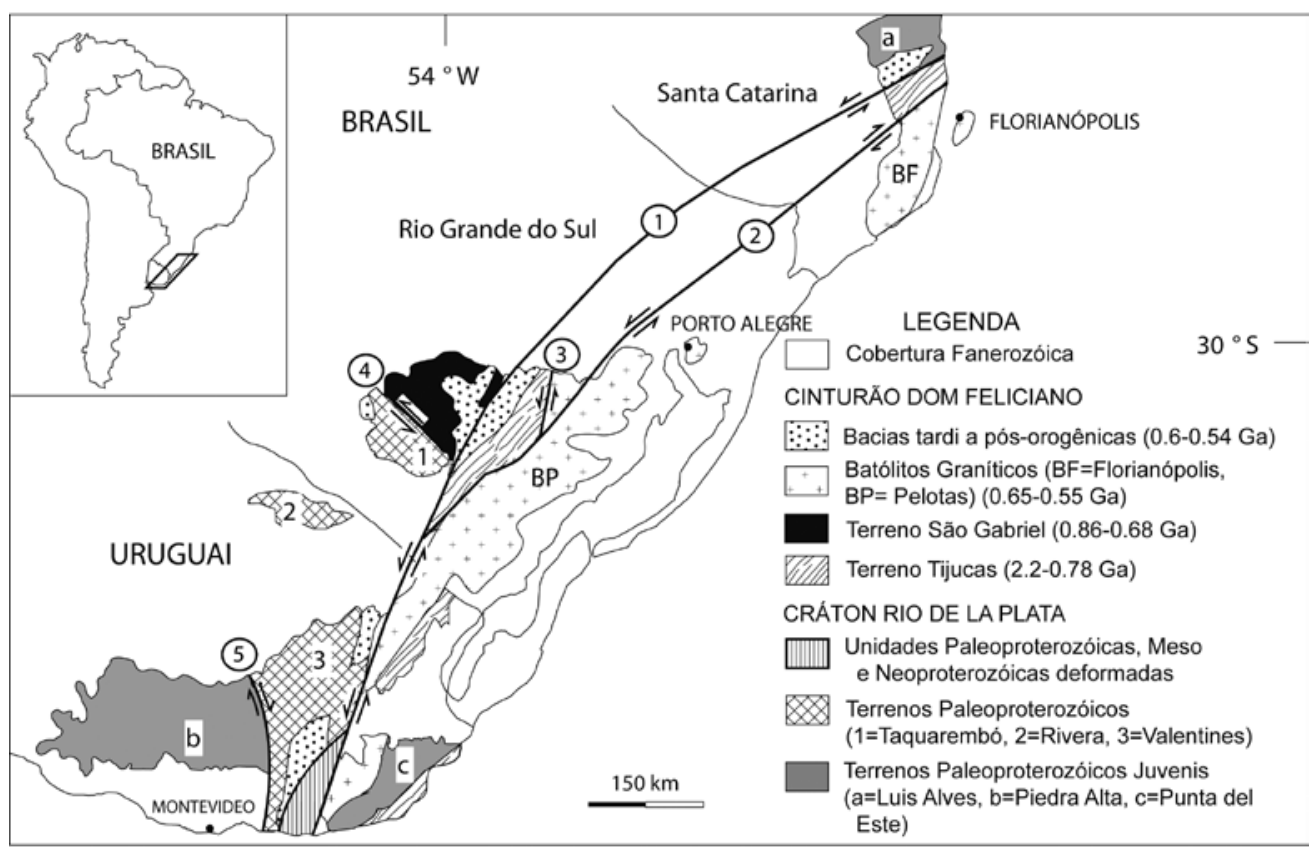

Figura 1 - Principais unidades geotectônicas do sul do Brasil e do Uruguai. Zonas de Cisalhamento: 1-Sierra Ballena-Caçapava do Sul, 2-Dorsal de Canguçu, 3-Passo dos Marinheiros, 4- Ibaré, 5-Sarandi Del Yi. Modificado de Hartmann et al. (2007). 

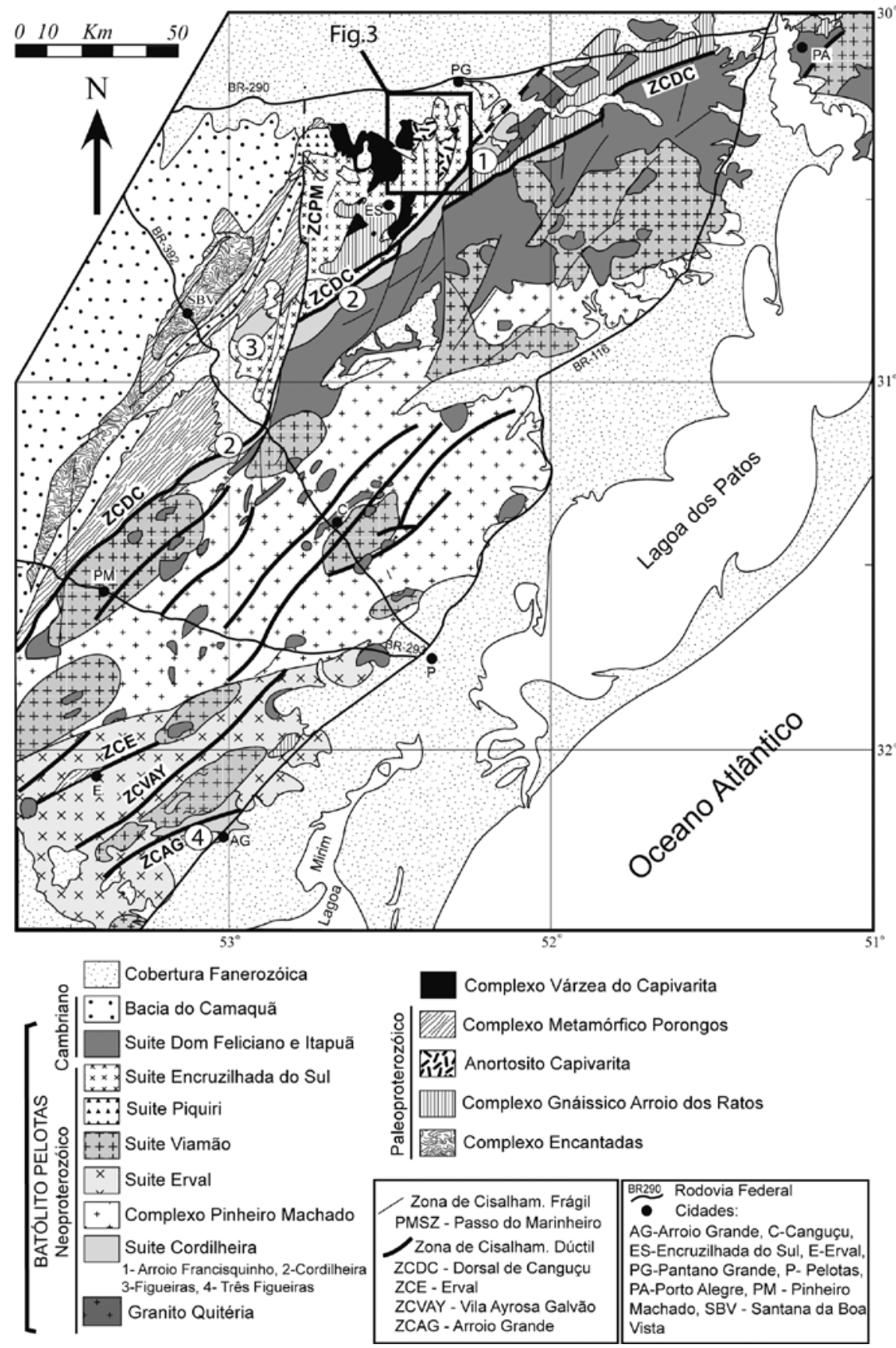

Figura 2 - Mapa geológico da porção central do Cinturão Dom Feliciano, destacando o Batólito Pelotas e a região da figura 3, destacando a área de localização do Anortosito Capivarita. Fonte: Philipp et al. (2007).

dos, com limites gradacionais de formas curvilíneas a retilíneas e são concordantes com o bandamento reliquiar (Fig. 4d). A granada, do tipo grossulária, apresenta forma globular e subédrica, com raras inclusões diminutas de plagioclásio e titanita com formas subédricas. Também mostra relações subpoiquilíticas com o plagioclásio dominante, que apresenta forma prismática tabular e subédrica. O teor de grossulária varia de 3 a $18 \%$.

$\mathrm{O}$ bandamento apresenta uma repetição rítmica e mostra relativa extensão lateral, considerando as áreas aflorantes. Na fazenda Porteirinha ocorre um corpo tabu- lar de anortosito com textura pegmatóide, caracterizado por cristais de plagioclásio com tamanhos entre 7 a 20 centímetros. Apresenta uma espessura entre 2 e 4 metros, disposição subparalela ao bandamento ígneo reliquiar, com contatos interlobados a curvilíneos e gradacionais.

No interior dos corpos anortosíticos ocorrem 5 corpos máficos. Os corpos possuem forma tabular e disposição concordante com o bandamento ígneo. Possuem espessuras entre 1 e 5 metros, limites definidos, retilíneos a curvilíneos, contatos interlobados com pequenas reentrâncias e apófises. Relações de contato 


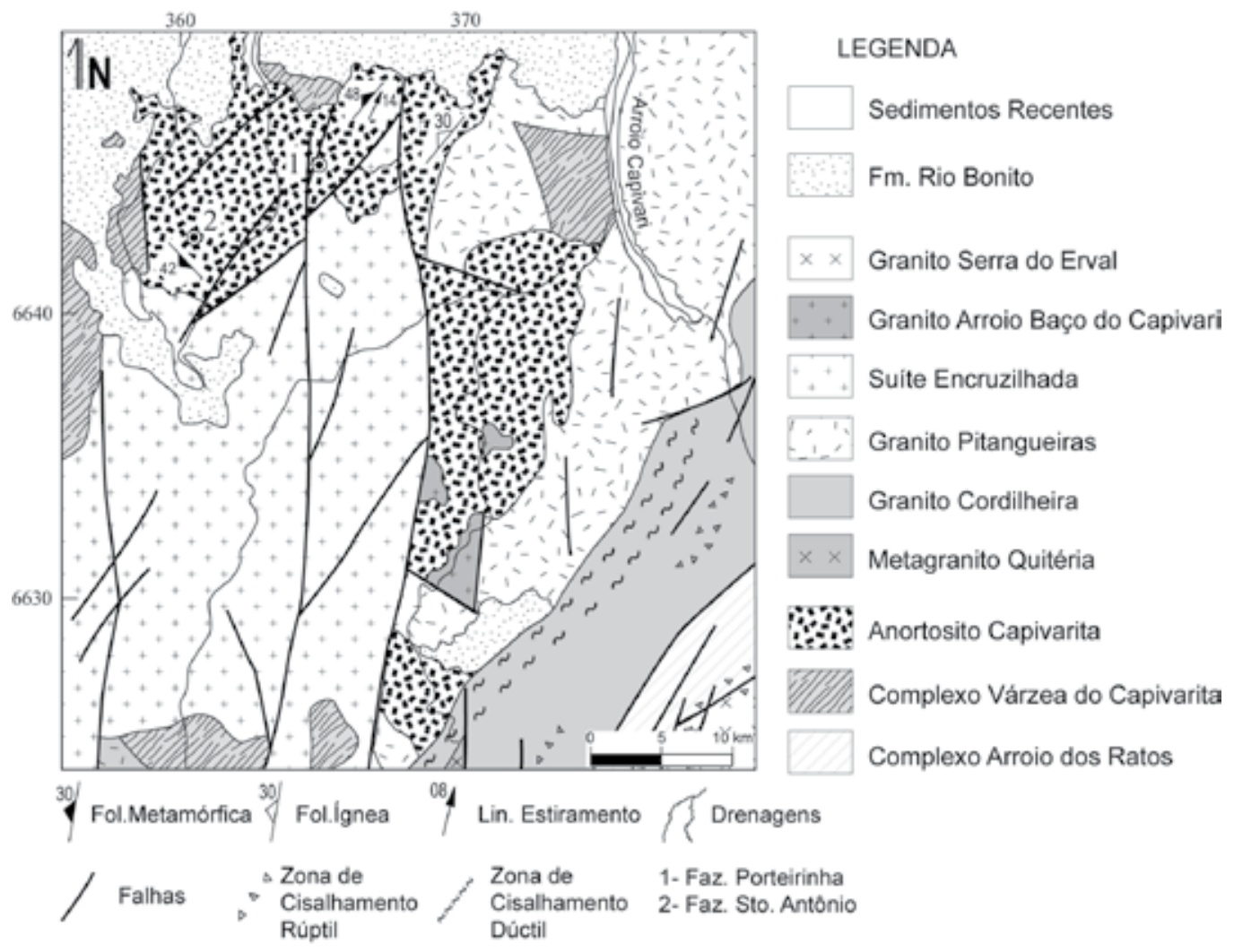

Figura 3 - Mapa geológico da região de Encruzilhada do Sul. Modificado de Ramgrab et al. (1993).
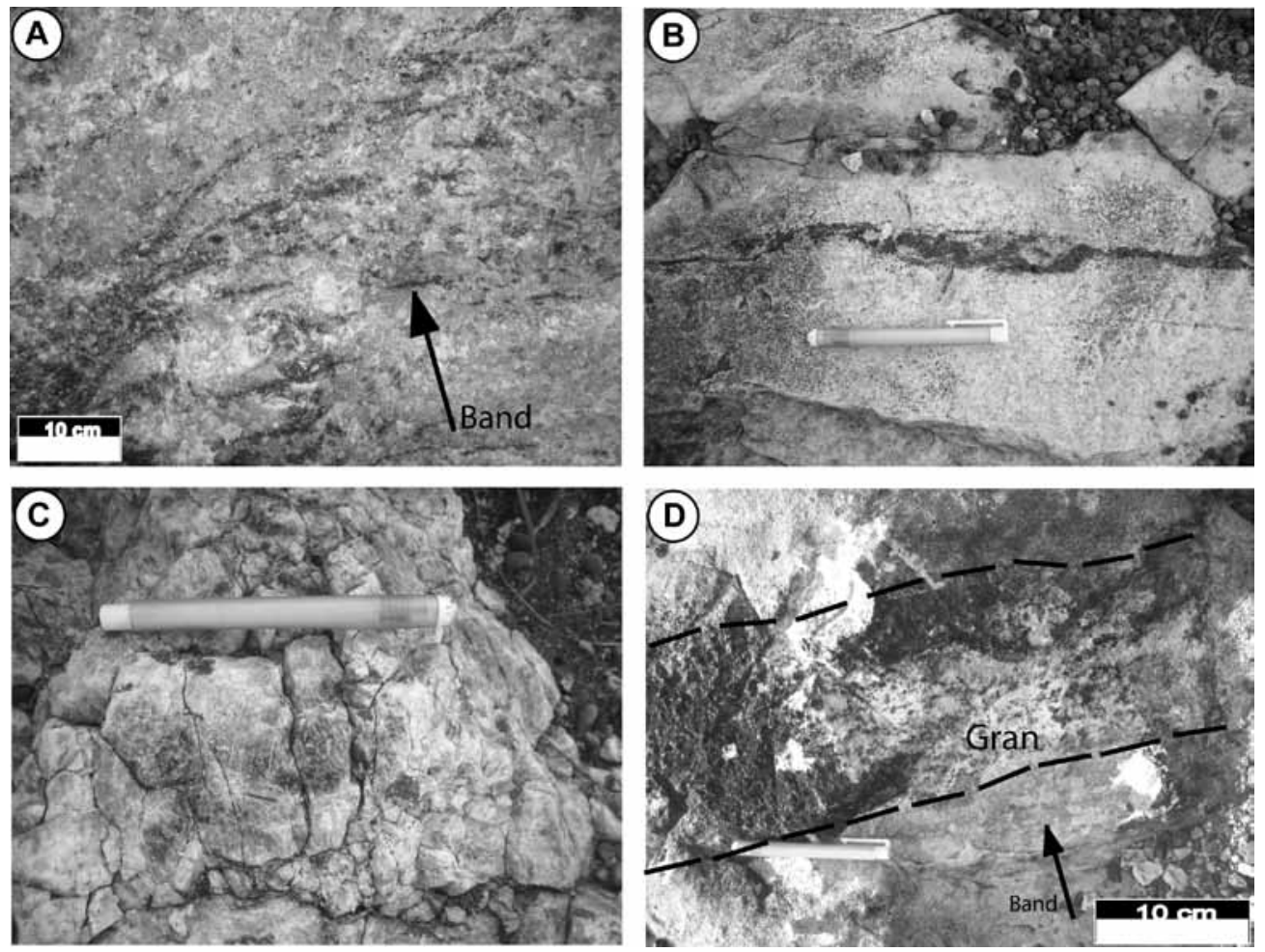

Figura 4 - Principais estruturas primárias do Anortosito Capivarita. A) Aspecto geral do bandamento incipiente e descontínuo marcado por minerais máficos; B) Bandamento irregular e contínuo definido por camada rica em hornblenda; C) Cristal de plagioclásio em anortosito com textura pegmatítica; D) Nivel de anortosito com granada com disposição concordante ao bandamento ígneo. 
ígneas foram observadas no principal afloramento da fazenda Porteirinha, definidas por três corpos de metagabros com espessuras de 30 e 50 centímetros (Fig. 5a). Os limites são definidos e possuem formas curvilíneas a interlobadas, ocorrendo pequenas apófises de metagabros, atestando o seu caráter parcialmente intrusivo (Fig. 5b). As formas curvilíneas das apófises e os limites interlobados, ressaltam a contemporaneidade da evolução magmática entre essas duas unidades (Fig. 5 c). Os metagabros têm cor preta e estrutura pouco foliada marcada pela orientação incipiente de hornblenda e biotita. Esta foliação está definida pela orientação dimensional de cristais máficos subédricos.

No principal afloramento da fazenda Sto. Antônio, ocorre um corpo de anfibolito deformado com espessura de 2 metros e disposição concordante ao bandamento do anortosito. $\mathrm{O}$ anfibolito tem cor preta e estrutura foliada marcada pela orientação de prismas alongados de hornblenda, definindo a textura nematoblástica e a lineação mineral (Fig. 5d).

Os dados de campo demonstram uma concordância entre as estruturas ígneas reliquiares e a foliação tectônica. Nos anortositos, observa-se uma disposição paralela entre os níveis de minerais máficos e a orientação dimensional da hornblenda na textura nematoblástica.
No afloramento da fazenda Porteirinha, há concordância entre o bandamento ígneo e a camada de anortosito com granada e também com o corpo anortosítico de textura pegmatóide, sugerindo que as relações de contatos entre estas unidades são comagmáticas e concordantes.

Nas duas principais áreas aflorantes estudadas, o anortosito apresenta uma orientação distinta do bandamento. Na fazenda Porteirinha, segundo a direção $\mathrm{N} 40^{\circ} \mathrm{E}$ com mergulhos entre 30 e $40^{\circ}$ para NW, acompanhado por uma lineação mineral com caimento de $15^{\circ}$ para a direção $\mathrm{N} 10^{\circ} \mathrm{E}$. Na fazenda Santo Antônio-Dom Felipe, o bandamento tem direção $\mathrm{N} 40^{\circ} \mathrm{W}$, com mergulhos de $40-50^{\circ}$ para SW. Esta variação pode estar relacionada a disposição espacial das duas principais ocorrências, que representam pendentes de teto nos Granitos Encruzilhada do Sul e Pitangueiras ou ainda poderia representar uma fase de dobramento regional, constituindo dessa maneira os dois flancos de uma dobra aberta com eixo principal direcionado para sul-sudoeste. Esta última hipótese não está descartada visto que os dados estruturais e as evidências de metamorfismo regional são concordantes com aquelas observadas nos complexos Várzea do Capivarita e Arroio dos Ratos, unidades metamórficas regionais que estão situadas a pouco metros do anortosito.
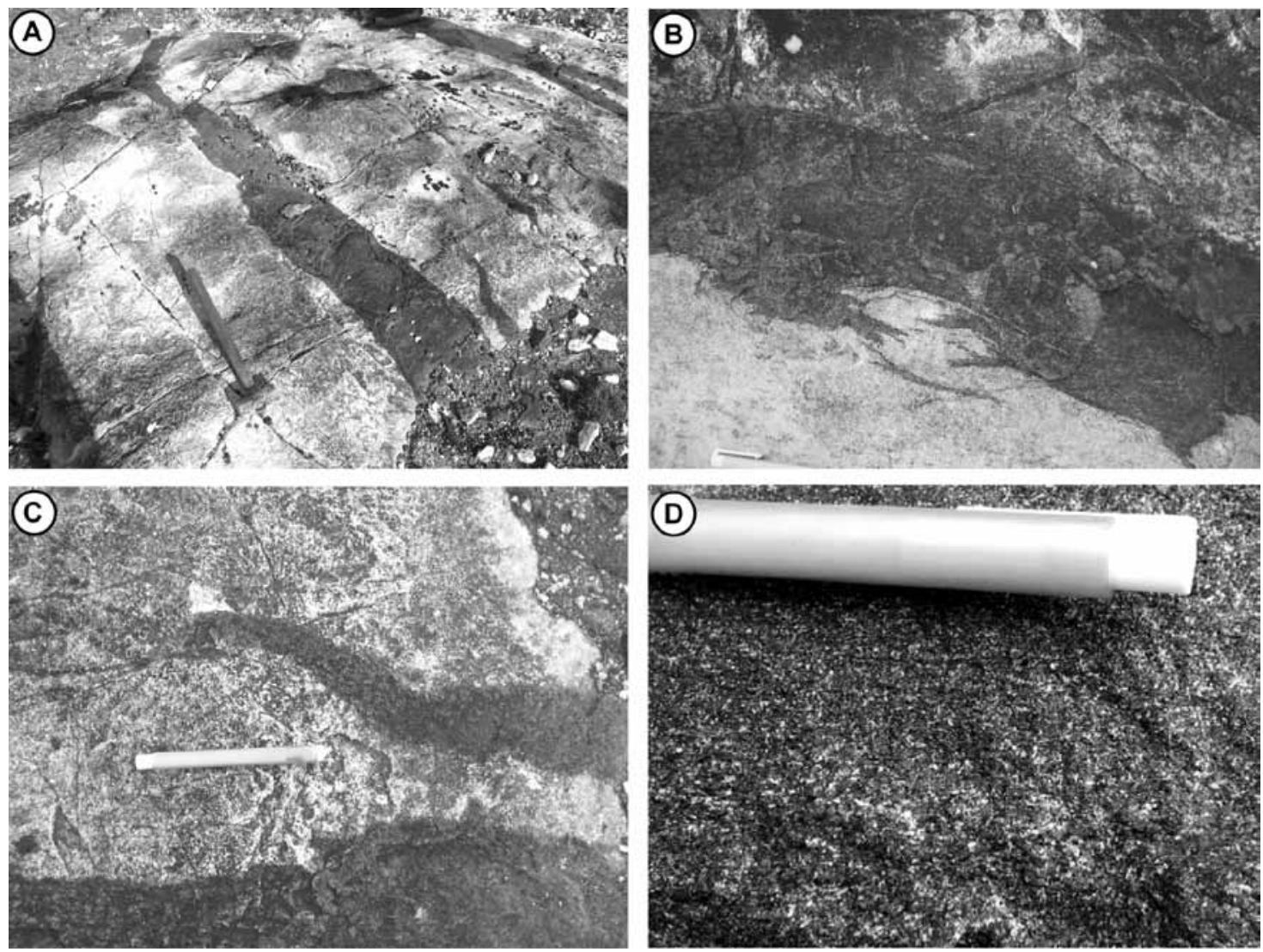

Figura 5 - Relações de contato com as rochas máficas. A) Corpos tabulares de metagabros com limites interlobados definindo um caráter intrusivo sob condições dúcteis, Fazenda Porteirinha; B) Detalhe das relações intrusivas com pequenas apófises de metagabro; C) Detalhe do contato de apófise de metagabro;D) Estrutura foliada em anfibolito com textura nematoblástica (Fazenda São Domingos). 


\section{PETROGRAFIA}

Anortosito Foram analisadas amostras dos dois tipos de anortositos. O tipo mais abundante é caracterizado pelo predomínio de plagioclásio, com baixos teores de anfibólio, enquanto a outra variedade petrográfica tem ocorrência restrita à fazenda Porteirinha e está caracterizada pela presença de granada como fase subessencial. Ambos os tipos petrográficos apresentam as mesmas características texturais, ocorrendo variação composicional através da proporção dos minerais, como pode ser observado na tabela 1 .

A principal textura do anortosito varia de blastoequigranular a blastoinequigranular média a grossa, caracterizada por porfiroclastos de plagioclásio com formas tabulares e tamanhos médios entre 5 e $30 \mathrm{~mm}$. Os cristais reliquiares constituem entre 20 e $55 \%$ e estão envoltos por agregados de plagioclásio metamórfico com arranjo granoblástico poligonal (Fig. 6a). Os espaços intersticiais são ocupados por agregados com hornblenda, titanita e minerais opacos, e por cristais isolados de grossulária, titanita, ilmenita, hornblenda e diopsídio. As variações texturais estão relacionadas a estrutura acamadada, ocorrendo níveis com espessuras métricas ( 2 a 7 metros) alternando anortosito equigranular médio a grosso $(5$ a $10 \mathrm{~mm})$ de cor branca e menos freqüente, anortosito inequigranular grosso de cor branca, com megacristais esparsos de plagioclásio de 2 a $5 \mathrm{~cm}$ envoltos por matriz equigranular média. Os megacristais têm cor branca com porções centrais de cor marrom claro, forma tabular, euédrico a subédrico, com limites retos a curvos (Fig. 6b). Ao microscópio mostram contatos interpenetrativos, macla polissintética e complexa, zonação normal e inclusões euédricas e diminutas de titanita, zircão e mais raramente grossulária (Fig. 6c). Subordinadamente, ocorre textura cumulática marcada por cristais intersticiais de plagioclásio na porção intercumulus. Neste caso, o plagioclásio tem forma amebóide, limites interlobados e contatos interpenetrativos. A textura protoclástica é definida por porfiroclastos de plagioclásio deformados, com formação de subgrãos limitados por contatos interlobados a subangulosos, com encurvamento da macla polissintética e extinção ondulante. Estas evidências indicam processos de deformação em estágio dúctil associado ao resfriamento e/ou a movimentações tardias associadas ao posicionamento do maciço anortosítico, ainda como uma pasta de cristais (mush crystals). As evidências texturais indicam a presença de uma mineralogia reliquiar composta por plagioclásio, titanita, magnetita, ilmenita, grossulária e zircão.

A principal textura metamórfica é granoblástica poligonal, equigranular a inequigranular média a grossa $(0,4$ a $1 \mathrm{~mm})$, com plagioclásio de forma poligonal, com limites retos, contatos a $120^{\circ}$ e macla polissintética (Fig. 6d). Menos freqüentemente, apresentam níveis de titanita, magnetita e ilmenita com textura granoblástica poligonal.

Tabela 1 - Análises modais de amostras representativas do Anortosito Capivarita e dos anfibolitos associados.

\begin{tabular}{|c|c|c|c|c|c|c|c|c|c|c|c|c|c|c|}
\hline Amostras & Plag & Gro & Diop & Horb & $\mathrm{Qz}$ & Tit & $\mathrm{Op}$ & $\mathrm{Bt}$ & Clo & Ser & Carb & Esc & Ep & Classif. \\
\hline A-69-01 & 95 & - & 0,7 & - & - & - & - & - & 2,2 & 1,1 & 0,3 & - & - & ANORT \\
\hline A-69-03 & 89 & - & 3,6 & 4,4 & - & 0,5 & 0,3 & - & 1,0 & - & 1,3 & 1,3 & - & ANORT \\
\hline A-69-05 & 97 & - & - & - & - & 0,2 & - & - & 2 & - & 0,5 & - & 0,3 & ANORT \\
\hline A-69-06 & 92 & - & - & 1,8 & - & 0,5 & - & 0,2 & 1,8 & - & - & - & 0,3 & ANORT \\
\hline A-69-07 & 97 & - & - & 1 & 0,4 & 0,2 & - & - & 1,0 & 0,2 & 0,4 & - & - & ANORT \\
\hline A-69-09 & 95 & - & 0,6 & - & 0,7 & 1,1 & - & - & 1,6 & 0,8 & - & - & 0,1 & ANORT \\
\hline A-69-11 & 94 & - & - & - & 0,6 & 0,1 & - & - & 1,5 & 3,6 & - & - & - & ANORT \\
\hline A-69-12 & 98 & - & - & - & 0,1 & 0,2 & 0,1 & - & 0,9 & - & 0,6 & - & - & ANORT \\
\hline A-69-13 & 97 & - & - & - & 0,3 & 0,1 & - & - & 0,3 & 2 & 0,7 & - & - & ANORT \\
\hline A-69-14 & 90 & - & - & - & 1,5 & - & - & 0,3 & - & 9 & - & - & - & ANORT \\
\hline A-69-15 & 95 & - & 1,6 & - & 0,8 & 0,5 & - & - & 1,8 & 0,1 & - & - & - & ANORT \\
\hline A-69-16 & 98 & - & - & 1 & 0,2 & 0,3 & 0,1 & - & 0,8 & 0,1 & - & - & - & ANORT \\
\hline A-69-17 & 98 & - & - & 1 & 0,1 & - & - & - & 0,6 & - & - & - & 0,4 & ANORT \\
\hline A-69-18 & 96 & 0,7 & - & - & 0,6 & 0,2 & - & - & 2,3 & 0,4 & 0,4 & - & - & ANORT \\
\hline CAP-70-12 & 85 & - & - & - & 8 & - & 1,5 & - & 5 & - & - & - & - & ANORT \\
\hline CAP-70-28 & 90 & - & - & - & 5 & - & - & - & 3 & 0,5 & - & - & - & ANORT \\
\hline CAP06/3 & 92 & 1 & - & 2 & 1 & 0,2 & 2 & - & 1 & 0,5 & - & - & 0,5 & ANORT \\
\hline CAP06/1 & 91 & - & - & 3,5 & 1,2 & 1,8 & 2 & - & 0,3 & 0,4 & - & - & 0,2 & ANORT \\
\hline $\mathrm{A}$ & 93 & 0,5 & - & 4,4 & 0,4 & 0,1 & - & - & - & - & - & 0,2 & 1,7 & ANGRO \\
\hline $\mathrm{B}$ & 91 & 0,8 & - & 4,7 & 0,6 & - & 0,1 & - & - & 0,1 & - & 2,3 & 0,6 & ANGRO \\
\hline A-69-04 & 85 & 2,6 & 1,0 & - & 3,6 & - & - & - & 7,4 & - & - & - & - & ANGRO \\
\hline CAP06/5 & 81 & 18 & - & - & & 0,2 & 1 & - & - & 0,3 & - & - & 0,5 & ANGRO \\
\hline A-69-02 & 27 & - & 0,7 & 60 & 9,8 & 0,8 & 0,6 & - & - & - & - & 0,9 & - & ANF \\
\hline A-69-10 & 35 & - & 4,4 & 56 & 4,6 & 0,1 & 0,1 & - & - & - & - & - & - & ANF \\
\hline CAP06/2A & 38 & - & 8,5 & 52 & 1 & 0,3 & 2 & - & - & - & - & - & - & ANF \\
\hline
\end{tabular}

Legenda: Classificação: ANORT - anortosito, ANGRO - anortosito com grossulária, ANF - anfibolito. Mineralogia: Plag - plagioclásio, Gro - grossulária, Diop - diopsídio, Horb - hornblenda, Qz - quartzo, Tit - titanita, Op - opacos, Bt - biotita, Clor - clorita, Ser - sericita, Carb - carbonato, Esc - escapolita, Ep - epidoto. 

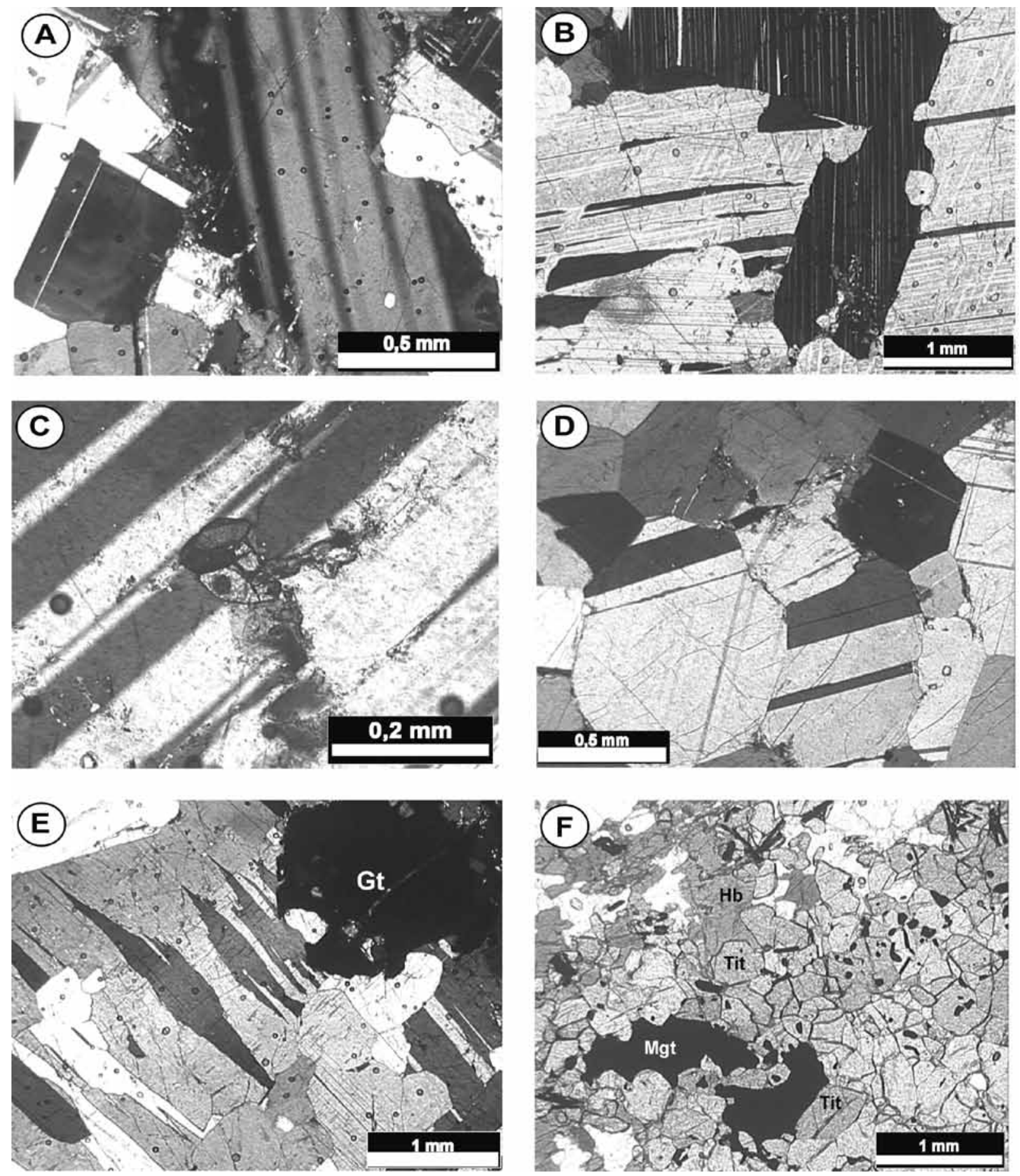

Figura 6 - Principais feições petrográficas do Anortosito Capivarita. A) Cristal reliquiar de plagioclásio com forma tabular envolto por grãos em vias de recuperação; B) Contato interpenetrativo entre cristais reliquiares de plagioclásio com macla polissintética; C) Inclusões de cristais euédricos de titanita em plagioclásio reliquiar; D) Textura granoblástica poligonal inequigranular média da matriz metamórfica; E) Relação subpoiquilítica entre cristal subédrico de granada Gt) e plagioclásio reliquiar com macla de interpenetração; F) Nível máfico descontínuo com acumulação de cristais máficos, estabilizados como um agregado de textura granoblástica poligonal contendo hornblenda (Hb), titanita (Tit) e magnetita (Mgt).

O nível de anortosito com granada apresenta textura blastoequigranular grossa definida por cristais reliquiares de plagioclásio com formas prismáticas subédricas. Os cristais de granada ocorrem isolados ou em agregados, são subédricos, intersticiais a subpoiquilíticos (Fig. 6e).

Ocorrem grãos de plagioclásio em vias de recuperação que apresentam zonação interna e limites definidos por duas ou três faces retas e as demais com 
formas interlobadas a curvilíneas. Outros grãos estão fragmentados com formação de subgrãos. Subordinadamente, a orientação dimensional de cristais subidioblásticos de hornblenda define a textura nematoblástica. No interior da hornblenda, ocorrem inclusões de ilmenita e plagioclásio com textura simplectítica. Os minerais metamórficos caracterizam uma paragênese com plagioclásio, hornblenda, diopsídio, grossulária, titanita e óxidos de Fe-Ti, indicativas de uma associação mineral com temperaturas mínimas equivalentes as da fácies anfibolito médio do metamorfismo regional orogênico (Butcher \& Frey 1994) (Fig. 6f).

As paragêneses ígnea e metamórfica estão afetadas por um evento hidrotermal mais jovem relacionado a intrusão dos granitos Encruzilhada do Sul e Pitangueiras. Este evento, caracterizado pela formação de uma mineralogia hidratada de baixa temperatura, tem distribuição irregular, concentrando-se nos limites externos dos corpos de anortosito e nos xenólitos. A alteração ocorre em faixas irregulares com espessuras comumente centimétricas e se manifesta pela formação de mica branca, clorita, pistacita e carbonato sobre o plagioclásio, clorita, pistacita e minerais opacos sobre clorita e clinozoisita sobre grossulária.

Análises da composição dos plagioclásios foram efetuadas por Formoso (1973) que caracterizou a presença dominante de labradorita, com ocorrência restrita de Anortita identificada somente no nível de anortosito com granada.

Metagabros e Anfibolitos Os metagabros possuem textura blastoinequigranular hipidiomórfica média ( 1 a $3 \mathrm{~mm}$ ) definida por uma trama de cristais de hornblenda e biotita, com espaços intersticiais ocupados por plagioclásio. Os minerais essenciais são anfibólio do tipo hornblenda, de cor castanha esverdeada e pleocroísmo entre verde escuro e castanho claro; biotita, de cor castanha alaranjada e pleocróica em tons de castanho claro a escuro; plagioclásio, do tipo labradorita, titanita, apatita e magnetita. Os minerais máficos têm formas prismáticas pouco alongadas e subédricas (Figs. 7a, 7b). Os plagioclásios ocorrem como cristais intersticiais e em agregados, têm forma prismática, pouco alongada a equidimensional, são subédricos, com macla polissintética e zonação normal (Fig. 7c).

A textura principal dos anfibolitos é nematoblástica média a grossa $(0.3$ a $1.2 \mathrm{~mm})$, com orientação dimensional de cristais subidioblásticos de hornblenda e, menos comumente de diopsídio (Fig. 7d). De modo subordinado, apresentam textura granoblástica inequigranular interlobada média $(0.2$ a $0.8 \mathrm{~mm})$, definida por arranjos poligonais de plagioclásio, diopsídio, titanita, ilmenita e magnetita. Em agregados de hornblenda de um dos corpos de anfibolitos, ocorre textura simplectítica caracterizada pelo intercrescimento vermiforme de magnetita com hornblenda. Este arranjo é sugestivo do desequilíbrio do piroxênio ígneo e do rearranjo para um novo equilíbrio metamórfico (Fig. 7f). A composição mineral é dominada por anfibólio do tipo hornblenda, de cor castanha esverdeada e pleocroismo entre verde escuro e castanho claro; plagioclásio, representado por uma labradorita, diopsídio, titanita e minerais opacos. O crescimento de diopsídio nos bordos dos cristais de hornblenda é indicativo de uma evolução progressiva a partir do aumento do grau do metamorfismo regional (Fig. 7e). A assembléia metamórfica com hornblenda + labradorita + diopsídio é característica de condições metamórficas mínimas equivalentes as da fácies anfibolito médio para as rochas máficas (Butcher \& Frey 1994). O plagioclásio dos anfibolitos também é a labradorita (Formoso 1973).

DISCUSSÃO Os dados de campo, petrográficos e mineralógicos indicam que o Anortosito Capivarita e os anfibolitos representam duas associações magmáticas distintas. A composição homogênea do plagioclásio, o baixo teor de minerais máficos e a ausência de rochas ultramáficas caracterizam o Anortosito Capivarita como do tipo maciço, a labradorita. A composição petrográfica e a composição mineral permitem reconhecer duas variedades de anortositos. $\mathrm{O}$ anortosito dominante é composto por plagioclásio do tipo labradorita, enquanto o anortosito com granada possui plagioclásio do tipo Anortita.

A ocorrência de plagioclásio com teores elevados de An e teores baixos de ortopiroxênio são indicados por Mayer et al. (2004) e Mukherjeet et al. (2005) como feições indicativas de anortositos maciços e de afinidade toleítica, gerados a partir de fontes mantélicas. Plagioclásio do tipo Bytownita, com teores de An entre 74 e 86 é descrito por Aït-Djafer et al. (2003) para os anortositos associados com intrusões acamadadas da Argélia. Neste caso, os autores descreveram nos gabros plagioclásio do tipo anortita com $\mathrm{An}_{94}$, indicando que a formação dos anortositos esteve relacionada com processos de acumulação de plagioclásio a partir de magmas máficos, gerados de fontes mantélicas empobrecidas.

No Anortosito Capivarita, o plagioclásio do tipo anortita ocorre restrito ao anortosito com granada, sendo interpretado por Formoso (1973) como produto da ação de processos de contaminação por paragnaisses encaixantes e/ou por metassomatismo hidrotermal relacionado a intrusão do Granito Encruzilhada do Sul. Entretanto, as relações petrográficas sugerem que as granadas têm origem ígnea e estão em equilíbrio com o plagioclásio reliquiar. A ocorrência de uma porção do corpo com plagioclásio de composição extrema poderia estar relacionada à cristalização de uma fase precoce a partir de um magma básico de afinidade toleítica, posteriormente separados por processos de flotação ou filter pressing. Novos estudos geoquímicos e isotópicos em desenvolvimento podem confirmar a origem dos anortositos com anortita e a relação com a possibilidade contaminação crustal (Philipp et al. 2010).

A presença de bandamento primário, com níveis de minerais máficos descontínuos e variação de tamanho de grão em camadas são feições estruturais indicativas da atuação de processos de cristalização fracionada com assentamento gravitacional e flotação. A disposição regular e acamadada sugere que o Anortosito Capivarita cristalizou a partir de uma câmara magmática alojada em 

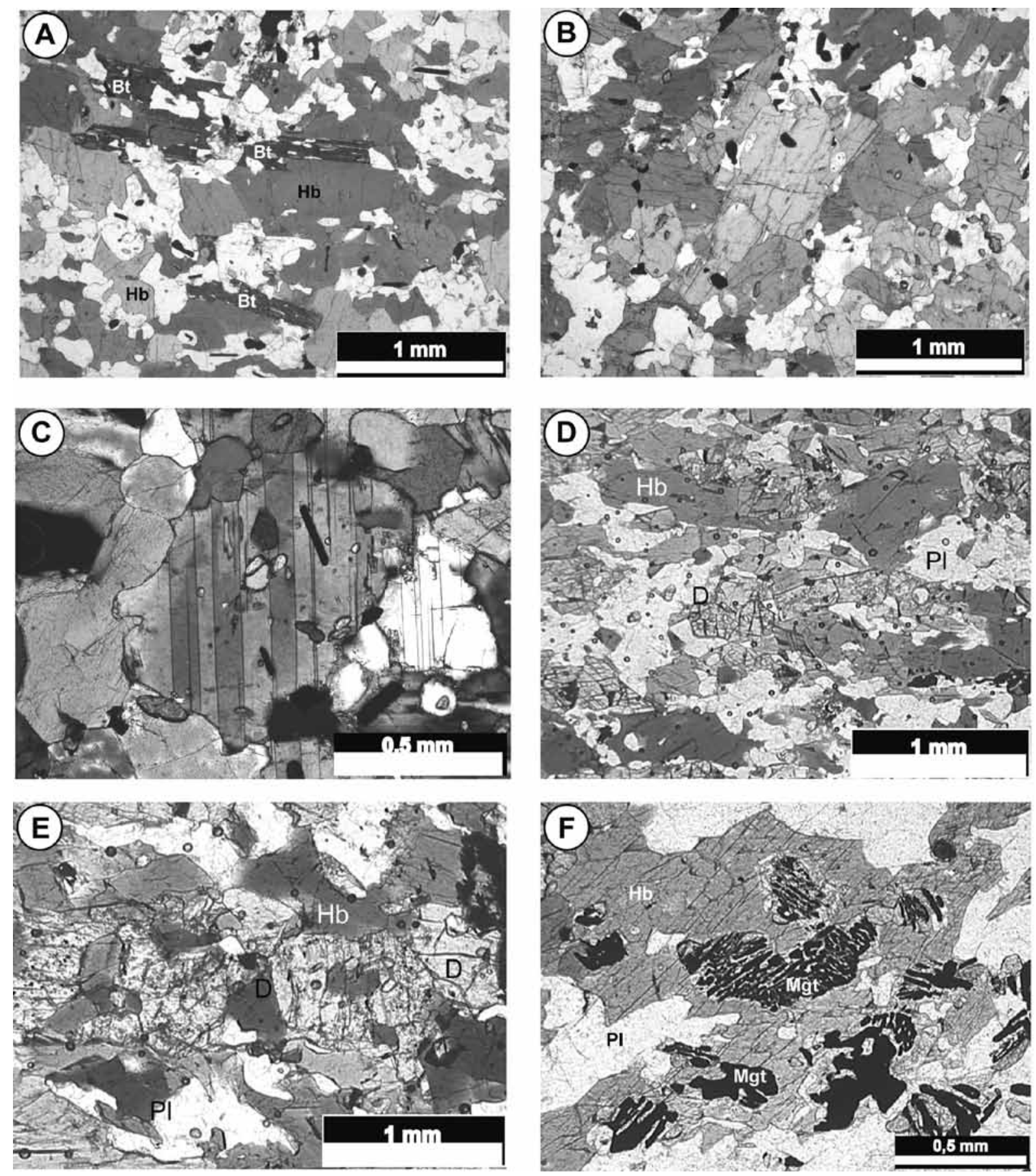

Figura 7 - Principais feições petrográficos dos metagabros e anfibolitos do Anortosito Capivarita. A) Textura blastoinequigranular em metagabro destacando cristais prismáticos reliquiares de hornblenda (Hb) e biotita (Bt) envoltos por matriz granoblástica com plagioclásio e hornblenda, B) Textura blastoinequigranular em metagabro com agregado de cristais prismáticos reliquiares de hornblenda, $C$ ) Cristal de plagioclásio reliquiar com inclusões euédricas de cristais de hornblenda, titanita e magnetita em metagabro, D) Textura nematoblástica em anfibolitos caracterizada pela orientação dimensional de hornblenda $(\mathrm{Hb})$ e diopsídio (D) com agregados de cristais poligonais de plagioclásio intersticiais, E) Destaque para cristais de diopsidio envolvendo cristais de hornblenda em anfibolitos, F) Textura simplectítica com intercrescimento de grãos vermiformes de hornblenda (Hb) e magnetita (Mgt).

um ambiente estável, sendo pouco afetada por processos de fluxo magmático e correntes de convecção associadas a fluxo térmico e/ou com concentrações de voláteis. Entretanto, a orientação dimensional de cristais prismáticos de plagioclásio é sugestiva da atuação localizada de processos de filter pressing.

A ocorrência de corpos máficos de disposição tabular, concordantes a subconcordantes com o banda- 
mento primário, e os contatos interlobados e intrusivos das rochas máficas indica que essas unidades são comagmáticas e têm uma evolução em parte simultânea com o anortosito. Dessa forma, as rochas máficas poderiam representar novos pulsos de fusão parcial, acrescendo os magmas máficos ao corpo de anortosito.

As feições petrográficas e composicionais do Anortosito Capivarita são similares aquelas encontradas em outros anortositos do tipo maciço de terrenos précambrianos como aqueles referidos por Ashwald (1993), Geringer et al (1998), Mukherjee et al. (2005), Morse (2006) e Drüppel et al. (2007), sendo compatíveis com magmas de composição toleítica e origem mantélica.

A associação do Anortosito Capivarita com os gnaisses do Complexo Várzea do Capivarita sugere que a evolução dessas unidades esteve relacionada com a evolução de um cinturão orogênico Brasiliano conforme discutido por Chemale Jr. (2000), Gross et al. (2006), Philipp et al. (2007) e Hartmann et al. (2007).

CONSIDERAÇÕES FINAIS As estruturas primárias sugerem que o Anortosito Capivarita evoluiu a partir de processos de fracionamento mineral a partir de um magma toleítico, provavelmente por flotação e filter pressing de plagioclásio. Os metagabros e anfibolitos associados mantêm relações de contato comagmáticas e concordantes com relação ao bandamento ígneo dos anortositos, indicando a recorrência do magmatismo máfico toleítico. A disposição regular do bandamento ígneo e suas características composicionais e texturais indicam que o magma que evolui para gerar o anortosito cristalizou em um ambiente estável.

O registro metamórfico observado no Anortosito Capivarita está relacionado com a evolução do Complexo Várzea do Capivarita e representa um evento de colisão continental do final do Ciclo Brasiliano. Estas considerações favorecem uma hipótese de geração e posicionamento em um período anorogênico, de estabilidade cratônica e provavelmente situado temporalmente entre as orogêneses do Paleoproterozóico e do Neoproterozóico.

Agradecimentos Somos gratos ao Centro de Estudos em Petrologia e Geoquímica (CPGq) do Instituto de Geociências da UFRGS pelo apoio nos trabalhos de campo. Esta pesquisa foi suportada pelo CNPq, Projeto PRONEX $N^{\circ} 04 / 0825-3$, e por bolsa de pesquisador do CNpq para os dois primeiros autores.

\section{Referências}

Aït-Djafer S., Ouzegane K., Paul-Liégeois J., Kienast J.R. 2003. An example of post-collsional mafic magmatism: the gabro-anorthosite layered complex from the Tin $\mathrm{Ze}$ bane area (western Hoggar, Algeria). Journal of African Earth Sciences, 37(3-4):313-330.

Areback H. \& Stigh J. 2000. The nature and origin of anorthosite associated ilmenite-rich leuconorite, Hakefjorden Complex, south-west Sweden. Lithos, 51:247267.

Ashwald L.D. 1993. Anorthosites. Heidelberg, Springer, 422 p.

Auwera J.V., Weis D., Duschesne J.C. 2006. Marginal mafic intrusions as indicator of downslope draining of dense residual melts in anorthositic diapirs? Lithos, 89(34):329-352.

Barnichon J.D., Havenith H., Hoffer B., Charlier R., Jongmans D., Duchesne J.C. 1999. The deformation of the Egersund-Ogna anorthosite massif, south Norway: finite-element modeling of diapirism. Tectonophysics, 303:109-130.

Bogdanova S.V., Pashkevic I.K., Buryanov V.B., Makarenko I.B., Orliuk M.I., Skobelev V.M., Starostenko V.I., Legostaeva O.V. 2004. Tectonophysics, 381(1-4):5-27.

Borradaile G.J., Lagroix F., King D. 1998. Tilting and transpression of an Archean anorthosite in northern Ontario. Tectonophysics, 293:239-254.

Butcher K. \& Frey M. 1994. Petrogenesis of Metamorphic Rocks. Berlin, Springer-Verlag, 317 p.

Charlier B., Duchesne J.C., Auwera J.V. 2006. Magma chamber processes in the Tellnes ilmenite deposit (Rogaland Anorthosite Province, SW Norway) and formation of $\mathrm{Fe}-\mathrm{Ti}$ ores in massif-type anorthosites. Chemical Geol- ogy, 234(3-4):264-290.

Charlier B., Sakoma E., Sauvé M., Stanaway K., Auwera J.V., Duchesne J.C. 2007. The Grader layered intrusion (Havre-Saint-Pierre Anorthosite, Quebec) and genesis of nelsonie and others Fe-Ti ores. Lithos, 101:359-378.

Chemale Jr. F. 2000. Evolução Geológica do Escudo Sul-riograndense. In: Holz M. \& De Ros L.F. (eds.) Geologia do Rio Grande do Sul. Porto Alegre: CIGO, p. 13-52.

Duschene J.C., Auwera J.V., Liégeois J.P., Barton E.S., Clifford T.N. 2007. Precambrian Research, 153(1-2):116142.

Drüppel K., Littmann S., Romer R.L., Okrusch M. 2007. Petrology and isotope geochemistry of the Mesoproterozoic anorthosite and related rocks of Kunene Complex, NW Namibia. Precambrian Research, 156(1-2):1-31.

Fernandes L.A., Tommasi A., Porcher C.C., Marques-Toigo M., Guerra-Sommer M., Piccoli A.M. 1988. Mapa geológico 1:50.000 de parte das folhas Quitéria e Várzea do Capivarita. Porto Alegre, Instituto de Geociências, UFRGS.

Formoso M.L.L. 1973. Geologia da folha Capivarita - RS, Anorthosito de Capivarita. Ph.D. Thesis, Instituto de Geociências, Universidade de São Paulo, São Paulo, 215 p.

Formoso M.L.L. \& Carraro C.C. 1968. Anorthosito de Capivarita, Rio Pardo, RS. Anais da Academia Brasileira de Ciências, 40:361-372.

Formoso M.L.L., Gorgoni C., Sighinolfi G. P. 1975. Petrology and Geochemistry of the Capivarita Anorthosite Massif (southern Brazil). Boll Soc Geol, x:1053-1069.

Geringer G.J., Schoch A.E., Sukanov M., Zhuravlev D. 1998. Geochemical and isotopic characteristics of dif- 
ferent types of anorthosite in the Namaqua mobile belt, South Africa. Chemical Geology, 145:17-46.

Gross A.O.M.S., Porcher C.C., Fernandes L.A.D., Koester E. 2006. Neoproterozoic low-pressure/high temperature collisional metamorphic evolution in the Varzea do Capivarita Metamorphic Suite, SE, Brazil: Thermobarometric and Sm/Nd evidence. Precambrian Research, 147:41-64.

Hartmann L.A., Chemale Jr. F., Philipp R.P. 2007. Evolução geotectônica do Rio Grande do Sul no Precambriano. In: Ianuzzi R. \& Frantz J.C.. (Org.) 50 anos de Geologia. Instituto de Geociências. Contribuicoes. 1 ed. Porto Alegre: Editora Comunicação e Identidade, CIGO. IGUFRGS, 1:97-123.

Heather D.J. \& Dunkin S.K. 2003. Geology and stratigraphy of King crater, lunar farside. Icarus, 163(2):307-329.

Higgins M. 2005. A new interpretation of the structure of Sept Iles Intrusive Suite, Canadá. Lithos, 83(3-4): 199213.

Lafrance B., John B.E., Frost R. 1998. Ultra high-temperature and subsolidus shear zones: an example from the Poe Mountain anorthosite, Wyoming. Journal of Structural Geology, 20(7):945-955.

Mayer A., Hoffmann A.W., Sinigoi S., Morais E. 2004. Mesoproterozoic Sm-Nd and U-Pb ages for the Kunene Anorthosite Complex of SW Angola. Precambrian Research, 133(3-4): 187-206.

Morse S.A. 2006. Labrador massif anorthosites: chasin the liquids and their sources. Lithos, 89(1-2):202-221.

Mukherjee D. \& Das S. 2003. Anorthosites, granulites and supercontinent cycle. Gondwana Research, 5(1):147156.

Mukherjee D., Naresh C.G., Chatterjee N. 2005. Crystalization history of a massif anorthosite in the eastern Indian shield margin based on borehole lithology. Journal of Asian Earth Sciences, 25(1):77-94.

Philipp R.P., Machado R., Chemale Jr. F. 2007. A Geração dos granitóides Neoproterozóicos do Batólito Pelotas: evidências dos isótopos de $\mathrm{Sr}$ e $\mathrm{Nd}$ e implicações para o crescimento continental da porção sul do Brasil. In: Ianuzzi R. \& Frantz J.C. (org.) 50 anos de Geologia Instituto de Geociências: Contribuções. $1^{\mathrm{a}}$ ed., Porto Alegre, Editora Comunicação e Identidade-CIGO-IG/ UFRGS, p. 59-77.

Philipp R.P., Formoso M.L.L., Dussin I., Chemale Jr. F. 2010. Petrology of Capivarita Anorthosite: a Mesoproterozoic massif anorthosite of the Dom Feliciano Belt, southern Brazil. Lithos, submitted.

Ramgrab G.E., Wildner W., Camozzato E. 1993. Porto Alegre - Folha SH.22-Y-B. Estado do Rio Grande do Sul. Escala 1:250.000. Programa de Levantamentos Geológicos Bá- sicos do Brasil. Brasília, CPRM, 200 p.

Reddy M.N. \& Leelanandam C. 2004. Magmatic and tectonic structures from the Chimalpahad Layered Complex, Andhra Pradesh, India. Gondwana Research, 7(3):887896.

Ribeiro M., Bocchi P.R., Figueiredo F.P., Tessari R.I. 1966. Geologia da Quadrícula de Caçapava do Sul, RGS. DNPM/DFPM, Rio de Janeiro, Boletim 127, 232 p.

Schenato F. \& Formoso M.L.L. 1993. Aspectos mineralógicos e geoquímicos da alteração do Anortosito Capivarita, RS. Geochimica Brasiliensis, 7(1):1-17.

Scoates J.S. \& Chamberlain K.R. 2003. Geochronological, geochemical and isotopic constrains on the origin of monzonitic and related rocks of Laramie Anorthosite complex, Wyoming, USA. Precambrian Research, 124(2-4):269-304.

Shumlyanskyy L., Ellam R.M., Mitrokhin O. 2006. The origin of basic rocks of the Korosten AMGC complex, Ukrainian shield: implication of $\mathrm{Nd}$ and $\mathrm{Sr}$ isotope data. Lithos, 90(3-4):214-222.

Takeda H., Yamaguchi A., Bogard D.D., Karouji Y., Ebihara M., Ohtake M., Saiki K., Arai T. 2006. Magnesian anorthosites and a deep crustal rock from the farside crust of the moon. Earth and Planetary Science Letters, 247(3-4):171-184.

Tessari R.I. \& Picada R.S. 1966. Geologia da quadrícula de Encruzilhada do Sul, RS, Brasil. DNPM/DFPM, Rio de Janeiro, Boletim 124, p.1-147.

Vasquez M. L. 1997. Evolução petrogenética dos granitos da Suite Intrusiva Encruzilhada do Sul - RS. Porto Alegre. Instituto de Geociências, Universidade Federal do Rio Grande do Sul, Dissertação de Mestrado, 195 p.

Wiedemann C.M., Medeiros S.R., Ludka I.P., Mendes J.C., Costa-De-Moura J. 2002. Architecture of late orogenic plutons in the Araçuaí-Ribeira fold belt, southeast Brazil. Gondwana Research, 5(2):381-399.

Wilson M. \& Overgaard G. 2005. Relationship between the layered Series and overlying evolved rocks in the Bjerkreim-Sokndal Intrusion, souther Norway. Lithos, 83(34):277-298.

Zhai M. \& Liu W. 2003. Paleoproterozoic tectonic history of North China craton> a review. Precambrian Research, 122(1-4):183-199.

Zhao G., Sun M., Wilde S.M., Sanzhong L. 2004. A PaleoMesoproterozoic supercontinent: assembly, growth and break-up. Earth-Science Reviews, 67(1-2):91-123.

Manuscrito ID 13830

Submetido em 06 de abril de 2009 Aceito em 02 de março de 2010 